\title{
PERKEMBANGAN SEKSUAL ANAK USIA DUA TAHUN (STUDI KUALITATIF PERKEMBANGAN SEKSUAL PADA ZAKIA)
}

\author{
WIDIA WINATA ${ }^{1-}$ KHAERUNNISA $^{2-}$ FARIHEN $^{3}$ \\ Universitas Muhammadiyah Jakarta, Indonesia \\ Email: widiakamek@gmail.com \\ pbsi.fipumj@gmail.com \\ farihens@gmail.com
}

\begin{abstract}
Early childhood sexual development has not received special attention in the curriculum or early childhood achievement standars (STPPA). Though sexual issues have become a national issue that has been demanding to look for a solution. This study was designed to discover how the stage of sexual development of two year olds (Zakia) as on overviewof preparation for further research in designing appropriate sexual education models. The research method used refers to qualitative naturalistic method with data collection technique through observation, documentation in the form of photo and video. The results showed two year old child (Zakia) was able to perform activities that lead to sexual development such as the introduction of anatomy, self recognition, adab and body hygiene. The aspect of sexual development is influenced by other aspects of development such as cognitive, language, motor, physical, social and emotional as well as aspects that come from outside himself such as weather and environment.
\end{abstract}

Keywords: developmental, sexual, two year old child

\begin{abstract}
Abstrak: Perkembangan seksual anak usia dini belum mendapat perhatian khusus dalam kurikulum atau Standar Tingkat Pencapaian Perkembangan Anak (STPPA) usia dini. Padahal persoalan seksual sudah menjadi isu nasional yang sudah menuntut untuk dicari penyelesaiannya. Penelitian ini didisain dengan tujuan untuk menemukan bagaimana tahap perkembangan seksual anak usia dua tahun (Zakia) sebagai gambaran persiapan untuk penelitian lanjutan dalam mendisain model pendidikan seksual yang sesuai. Metode penelitian yang digunakan merujuk pada metode kualitatif naturalistik dengan teknik pengumpulan data melalui observasi, dokumentasi berupa foto dan video. Hasil penelitian memperlihatkan bahwa anak berusia dua tahun (Zakia) sudah mampu melakukan kegiatan yang mengarah pada pengembangan seksualnya seperti pengenalan anatomi tubuh, pengenalan diri, adab dan kebersihan tubuh. Aspek perkembangan seksual dipengaruhi oleh aspek pengembangan lain seperti kognitif, bahasa, fisik motorik, sosial dan emosional serta aspek yang berasal dari luar dirinya seperti cuaca dan lingkungan.
\end{abstract}

KataKunci: $\quad$ perkembangan, seksual, anak usia dua tahun

PENDAHULUAN

Proses pencapaian kematangan

seksual dimulai pada saat pembuahan dan berakhir pada saat kematian. Hal ini dipengaruhi oleh kematangan biologis yang sesuai 
dengan tahap perkembangan anak. Faktor lain yang turut mempengaruhi adalah pengaruh lingkungan seperti orang tua dan teman. Kekuatan ini membentuk jenis kelamin, identitas seksual dan perilaku seksual anak di masa depan (Delamater, 2010: 10).

Memperhatikan

perkembangan seksual anak sama pentingnya dengan memperhatikan perkembangan kognitif, sosial emosional atau perkembangan fisik motoriknya. Namun saat ini pendidik di rumah maupun prasekolah masih berfokus pada aspek perkembangan kognitif, sosial emosional dan fisik motorik saja. Hal ini terlihat dalam standar acuan nasional tentang Standar Tingkat Pencapaian Perkembangan Anak (STPPA) untuk anak usia dini. STPPA merupakan standar isi, proses, penilaian, pendidik dan tenaga kependidikan, sarana dan prasarana, pengelolaan serta pembiayaan dalam pengelolaan dan penyelenggaraan pendidikan anak usia dini. STPPA digunakan juga sebagai acuan dalam menyusun kurikulum pendidikan anak usia dini di Indonesia (Peraturan Menteri
Pendidikan dan Kebudayaan, Nomor 137, 2014: pasal 5).

Secara spesifik aspek perkembangan anak yang dimaksud dalam STPPA memuat aspek nilai agama dan moral, fisik motorik, kognitif, bahasa, sosial emosional dan seni (Peraturan Menteri Pendidikan dan Kebudayaan, Nomor 137, 2014: pasal 7). Aspek perkembangan seksual belum dicantumkan secara jelas dan tegas. Padahal permasalahan seksual sudah menjadi isu nasional yang dibahas dalam berbagai forum, media dan wilayah di Indonesia.

Komisi Perlindungan Anak Indonesia (KPAI) mencatat 1.726 kasus pelecehan seksual yang terjadi selama tahun 2015 lalu, 58\% nya dialami oleh anak-anak. Data ini semakin bertambah jika dibandingkan dengan tahun sebelumnya yakni 52\% korban anakanak (http://news.okezone.com). Ini memperlihatkan betapa wajah anak Indonesia menjadi sorotan untuk lebih diperhatikan dari sisi pendidikan seksualnya. Pemerintah telah melakukan berbagai upaya untuk menanggulangi kasus 
kejahatan seksual pada anak dari sisi hukum dan kepolisian, namun akar persoalan yang mendasar belum dituntaskan. Persoalan dasar yang dimaksud adalah sisi pendidikan, baik korban maupun pelaku adalah sama-sama manusia yang harus dididik seksualitasnya. Ada juga upaya yang dilakukan lembaga swadaya masyarakat, di antaranya melakukan aksi "mari bicara" yang membuat para korban berani menyatakan bahwa ia mengalami kekerasan seksual oleh orang tertentu bahkan oleh orang tuanya sendiri (Metro TV; Mata Najwa, ejournal.unesa.ac.id). Namun cara ini dilakukan setelah seseorang menjadi korban. Alangkah baiknya jika pendidikan dilakukan sebagai tindakan preventif agar tindakantindakan kejahatan itu tidak terlanjur terjadi.

Sebelum membentuk sebuah model pendidikan seksual yang cocok, tentunya seorang pendidik harus mengetahui terlebih dahulu bagaimana tahap perkembangan seksual anak sejak dilahirkan sampai ia dewasa. Namun karena luasnya pemahaman tersebut maka penelitian ini dibatasi pada analisis perkembangan seksual anak usia dua tahun yang bernama Zakia. Kajian ini mengantarkan pada pemahaman bahwa anak memiliki tahap perkembangan yang khas dan berbeda di tahapan usia-usia berikutnya. Tujuan penelitian ini adalah untuk menemukan konteks aspek perkembangan seksual anak berusia dua tahun.

\section{KAJIAN TEORITIK}

\section{Perkembangan Seksual Anak}

Perkembangan seksual adalah perkembangan yang terkait dengan sexual, berarti sex or the sexes. Sedangkan sex or the sexes merujuk kepada makna state of being male or female; keadaan/status menjadi lakilaki atau perempuan (Oxford Dictionary, 2015; 403). Pengertian seksual disebut juga dengan hal yang berkenaan dengan seks (jenis kelamin); berkenaan dengan perkara persetubuhan antara laki-laki dan perempuan (Kamus Bahasa Indonesia; 358). Namun tidak semua pakar setuju bahwa seks selalu berhubungan dengan perkara persetubuhan. 
Salah satu tulisan dalam artikel Alodokter mempertegas bahwa tidak selamanya seksual dikaitkan dengan urusan persetubuhan yang banyak dipandang sebagai hal yang tabu untuk diperbincangkan. Menurutnya, seksual adalah segala sesuatu tentang anatomi tubuh dan pengenalan diri sendiri seperti nama-nama anggota tubuh, kebersihan tubuh dan informasi lain yang terkait dengan anatomi tersebut. Jika dikaitkan dengan pembelajaran, maka seksual adalah proses pembelajaran tentang anatomi tubuh dan pengenalan diri sendiri (www.alodokter.com).

Begitu pula dalam penelitian yang dilakukan Paramastri, Supriyati dan Priyanto disebutkan bahwa pembelajaran seksual adalah pembelajaran tentang jenis kelamin laki-laki dan perempuan, perbedaannya dan hal yang boleh dan tidak boleh dilakukan (adab). Model yang bisa digunakan dalam pelaksanaannya bisa berupa model prevensi dini; teknik diskusi kelompok dan cerita komik (Jurnal Psikologi. Volume 37, 2010; 10).
Perkembangan seksual anak sebenarnya sudah bisa dikaji secara terbuka di jaman sekarang ini. Berbeda dengan dahulu jika bicara seksual dianggap tabu, saat ini dunia pendidikan sudah sangat berkembang. Orang tua bisa saling terbuka memberikan informasi terhadap hal yang berkaitan dengan perkembangan seksual anaknya (Frankham, 2006: 1).

Berdasarkan kajian tersebut dapat disimpulkan bahwa perkembangan seksual adalah perkembangan yang terkait dengan anatomi tubuh dan pengenalan diri sendiri seperti jenis kelamin laki-laki dan perempuan, perbedaannya, hal yang boleh dan tidak boleh dilakukan (adab), nama-nama anggota tubuh, kebersihan tubuh dan informasi lain yang terkait dengan anatomi tersebut.

\section{Prinsip Perkembangan Seksual} Anak

Menurut pandangan ajaran agama Islam, perkembangan seksual anak perlu diperhatikan secara seimbang dengan perkembangan aspek lainnya. Perkembangan seksual anak diarahkan dengan 
memperhatikan prinsip-prinsip

sebagai berikut;

1. Meminta izin. Ajarkan anak untuk meminta izin jika masuk ke kamar orang tua pada saat orang tua sedang istirahat.

2. Menjaga aurat. Ajarkan anak menutup auratnya jika keluar rumah dan bertemu orang lain.

3. Memisahkan tempat tidur anak ketika anak sudah memasuki usia 10 tahun.

4. Tidur dalam keadaan miring ke kanan. Posisi ini membuat organ tubuh lebih rileks dan dapat menghindari berbagai penyakit.

5. Istirahat yang cukup dengan cepat tidur di malam hari dan cepat bangun di pagi hari.

6. Menghindari pergaulan bebas antara laki-laki dan perempuan.

7. Orang tua menjadi contoh bagi anak-anaknya. Dalam segala hal, orang tua menjadi teladan bahkan dalam urusan berhubungan badanpun orang tua harus memperhatikan jangan sampai terlihat oleh anak.

8. Mengajarkan anak tata cara mandi. (Al Magribi, 2006: 334$353)$.
9. Tidak dicium oleh bukan muhrim.

10. Tidak bermain-main dengan alat kelamin anak. Hal ini secara tidak langsung merupakan kategori pelecehan dan dapat menimbulkan rangsangan (Reysyahri, 2009: 134).

Tujuan perkembangan seksual tersebut dimaksudkan agar harga diri dan keselamatan organ reproduksi dapat terjaga dengan baik sesuai dengan tahap perkembangannya. Persiapan untuk mencapai tujuan ini dilakukan sejak anak berusia dini atau sejak anak dilahirkan (Reysyahri, 2009: 134), bahkan sejak terjadi pembuahan. Jika dapat dirangkum dalam sebuah sketsa tabel, maka perkembangan seksual anak usia dua tahun mencakup unsur yang terkandung berikut ini:

Tabel 1. Perkembangan Seksual Anak Usia Dua Tahun

\begin{tabular}{|l|l|}
\hline \multicolumn{1}{|c|}{ Aspek } & \multicolumn{1}{c|}{ Rincian } \\
\hline Anatomi tubuh & $\begin{array}{l}\text { Nama anggota } \\
\text { tubuh }\end{array}$ \\
\hline Pengenalan diri & $\begin{array}{l}\text { Nama panggilan, } \\
\text { Jenis kelamin }\end{array}$ \\
\hline Adab & Menutup aurat, \\
\hline $\begin{array}{l}\text { Kebersihan } \\
\text { tubuh }\end{array}$ & $\begin{array}{l}\text { Toilet training; } \\
\text { menggosok gigi, } \\
\text { mandi }\end{array}$ \\
\hline
\end{tabular}


Tahap Perkembangan Seksual

\section{Anak}

Tahap perkembangan seksual anak dimulai sejak anak dilahirkan. Tahap perkembangan seksual anak tersebut mengikuti fase yang berbeda antara satu dengan yang lainnya. Frued menyusun fase tersebut dengan beberapa tahap yaitu oral stage, anal stage, phallic stage, latency stage dan genital stage (Frued dalam Garcia, 1995: 1).

1. Tahap mulut (oral stage), berlangsung sejak anak dilahirkan sampai berusia 12-18 bulan. Puncak kenikmatan bayi berada di mulutnya; mengunyah, menghisap dan menggigit dapat mengurangi tekanan yang dialami bayi.

2. Tahap anal (anal stage) berlangsung sejak usia 12-18 bulan hingga berusia tiga tahun. Pada saat ini pengenalan toilet training bisa dilakukan karena anak sudah memiliki sensitifitas dengan anus.

3. Tahap phallic (phallic stage) berlangsung sejak anak berusia tiga sampai enam tahun. Phallic berasal dari kata phallus yang berarti alat kelamin laki-laki; pusat kenikmatan berada pada alat kelamin.

4. Tahap laten (latency stage) berlangsung saat anak berusia enam tahun hingga pubertas. Saat ini anak menaruh perhatian sangat khusus pada masalah seksual dan mengembangkan keterampilan sosial serta intelektualnya.

5. Tahap genital (genital stage) masa ini berlangsung sejak pubertas hingga masa dewasa (Papalia, 2009; 27).

Tahap perkembangan seksual ini tidak berdiri sendiri. Menurut Freud perkembangan alami manusia selalu terhubung antara perkembangan biologis, sosial dan emosional (Seefeldt, 1994: 36). Oleh karena itu, pakar setelah Frued mengkaji pandangan lain seperti perkembangan emosional. Di antara pakarnya adalah Ericson. Ia mengatakan bahwa anak di usia dua tahun sudah memiliki kemandirian untuk melakukan aktivitas yang dirasa mampu untuk ia lakukan (autonomy) (Papalia, 2009; 27). 
Aspek lain yang turut dibahas adalah kematangan dalam satu perkembangan. Kematangan seksual itu terjadi jika unsur-unsur lain seperti fisik motorik juga turut mendukung perkembangan tersebut. Pada usia dua tahun anak sudah mampu berinteraksi dengan lingkungannya, memilih dengan siapa ia nyaman untuk berteman. Bermain dengan berbagai alat permainan yang lebih bervariasi dan meniru peran-peran yang biasa ia lihat sehari-hari. Anak juga sudah memiliki bentuk temperamen yang khas bila ia sedang tidak nyaman. Jika pada usia dua tahun ini anak mendapatkan attachments yang baik dari keluarganya maka komunikasi di luar dengan teman dalam membentuk kelekatan juga akan semakin membaik (McDevitt, 2004: 584).

\section{METODE PENELITIAN}

Penelitian ini menggunakan metode penelitian kualitatif untuk menggambarkan kondisi perkembangan seksual anak usia dua tahun. Sesuai dengan tujuan penelitian untuk mengetahui perkembangan seksual anak usia dua tahun maka subjek yang diteliti adalah anak berusia dua tahun bernama Zakia AW. Zakia merupakan anak kedua dari dua bersaudara. Orang tua Zakia berinisial AY dan WW berprofesi sebagai wiraswasta dan dosen di sebuah universitas swasta di Jakarta. Keluarga Zakia berdomisili di Bogor dan memiliki status sosial ekonomi yang cukup baik.

Penelitian ini dirancang
sebagai dasar untuk melakukan
penelitian lanjutan berupa penciptaan
model. Sebelum menghasilkan model pendidikan seksual untuk anak usia dini, perlu dilakukan penelitian kualitatif dengan teknik naturalistik agar terlihat tahap perkembangan seksual anak secara alami atau disebut juga dengan istilah inkuiri ilmiah (Moleong, 2002: 15). Penelitian ini dilaksanakan selama kurun waktu delapan bulan sejak Januari 2017 sampai dengan Agustus 2017.

Teknik pengumpulan data dilakukan dengan observasi partisipan, dokumentasi berupa foto dan video. Hasil observasi dicatat 
dalam catatan harian seperti mencatat aktivitas harian anak yang terkait dengan fokus penelitian. Kegiatan bermain dan kegiatan seperti membersihkan tangan sesudah bermain, memasang baju atau kondisi persiapan ke toilet.

Makna partisipan dalam penelitian ini adalah ikut serta dalam situasi sosial yang diteliti, mengikuti segala aktivitas anak, bukan saja melihat tetapi ikut melebur dengan anak dalam melayaninya dan menyelesaikan permasalahannya (Spradley, 1980: 53). Dengan demikian dapat dimaknai bahwa instrumen penelitian adalah peneliti sendiri.

Teknik

pemeriksaan keabsahan data menggunakan teknik perpanjangan keikutsertaan, ketekunan pengamatan, triangulasi, pengecekan sejawat melalui diskusi dan kecukupan referensial data (Moleong, 2002: 178). Pengecekan rekan sejawat mengundang pakar parenting dan literasi Ir. Adiyati Fathu Roshonah, M.Pd dalam mengecek kebenaran aspek dan indikator perkembangan seksual anak usia dua tahun yang sudah disusun oleh peneliti (20 Juli 2017).

Proses analisa data dilakukan dengan menelaah seluruh data yang tersedia, mereduksi data dengan cara membuat abstraksi data. Abstraksi ini dibuat dengan bentuk rangkuman agar inti sari data dapat terjaga. Kemudian menyusun data itu ke dalam satuan-satuan, selanjutnya mengkategorikan dengan memberi kode data (Moleong, 2002: 190). Sambil memberi kode dan memilih, peneliti dapat melaksanakan pemeriksaan keabsahan data jika ada yang kurang atau tidak sesuai. Hasil akhir analisis ini ditafsirkan dan dilaporkan.

\section{HASIL DAN PEMBAHASAN}

\section{Deskripsi Data}

Berdasarkan data yang diperoleh dari subjek penelitian bahwa tahap perkembangan seksual Zakia dipengaruhi oleh beberapa aspek, di anataranya adalah;

1. Kematangan aspek biologis dan fisik motorik Zakia. Di usia dua tahun ia sudah mampu berjalan dengan baik menuju toilet untuk 
Perkembangan Seksual Anak...

Widia Winata, Khaerunnisa,\&Farihen

membersihkan diri, misalnya mencuci tangan atau membasuh kotoran yang menempel di tubuhnya tanpa dibantu orang tua. Kemampuan fisik lainnya, di antaranya adalah;

Tabel 2. Perkembangan Fisik

Zakia

\begin{tabular}{|l|l|}
\hline \multicolumn{1}{|c|}{ Motorik Halus } & \multicolumn{1}{|c|}{ Motorik Kasar } \\
\hline minum dari botol & main kuda-kudaan \\
\hline $\begin{array}{l}\text { memasukkan } \\
\text { benda ke dalam } \\
\text { gelas }\end{array}$ & $\begin{array}{l}\text { bergerak mengikuti } \\
\text { irama lagu }\end{array}$ \\
\hline $\begin{array}{l}\text { memberi minum } \\
\text { boneka }\end{array}$ & $\begin{array}{l}\text { menaiki sepeda roda } \\
\text { tiga }\end{array}$ \\
\hline $\begin{array}{l}\text { membubuhkan } \\
\text { odol di sikat gigi }\end{array}$ & $\begin{array}{l}\text { meniru kegiatan } \\
\text { menyapu/mengepel } \\
\text { /mengelap meja }\end{array}$ \\
\hline menggosok gigi & $\begin{array}{l}\text { menumpuk catrige } \\
\text { bekas menjadi tujuh } \\
\text { tingkat }\end{array}$ \\
\hline $\begin{array}{l}\text { berkumur-kumur } \\
\text { Melompat }\end{array}$ \\
\hline $\begin{array}{l}\text { Memasukkan } \\
\text { pensil ke dalam } \\
\text { kotak }\end{array}$ & Memanjat \\
\hline mencoret di buku & Berlari \\
\hline $\begin{array}{l}\text { memencet tombol } \\
\text { pianika }\end{array}$ & Naik tangga \\
\hline
\end{tabular}

2. Perkembangan aspek kognitif juga mempengaruhi aspek perkembangan seksual anak. Kemampuan Zakia juga tidak lepas dari perkembangan kognitif dan bahasa yang membuat ia harus mengungkapkan kehendak. Bunyi vokal dan konsonan yang masih terbatas namun bisa dimengerti dengan bantuan bahasa tubuh sehingga orang tua mengerti dengan apa yang dimaksudkan. Misalnya, ketika hendak buang air kecil ia mengatakan "pipis" dan meniru gerakan menjongkok. Ketika mau buang air besar ia melepaskan celana sambil memegang anusnya dan berjongkok. Jika keinginannya tidak direspon, maka menangis menjadi alternatif yang mudah dilakukan untuk menarik perhatian orang yang berada di sekitarnya. Tindakan ini dilakukan ketika hasrat buang air terjadi spontan sebelum Zakia sampai di toilet.

Tabel 3. Pemerolehan Bunyi Vokal dan Konsonan Zakia

\begin{tabular}{|l|l|}
\hline \multicolumn{1}{|c|}{ Bunyi } & \multicolumn{1}{c|}{ Makna } \\
\hline Mi & Umi \\
\hline Abi & Abi \\
\hline Mpis & Hafiz (abangnya) \\
\hline Iya & Zakia \\
\hline Dudu & duduk \\
\hline Ita & Ikan \\
\hline Uwe & kue \\
\hline Upuk & kerupuk \\
\hline Cih & terima kasih \\
\hline Ama & sama-sama \\
\hline Pipi & Upin dan Ipin \\
\hline Toto & motor \\
\hline Mam & makan \\
\hline Num & minum \\
\hline Cucu & Susu \\
\hline
\end{tabular}




\begin{tabular}{|l|l|}
\hline Atuh & Jatuh \\
\hline Pipis & Buang air kecil \\
\hline Ew & Kucing \\
\hline
\end{tabular}

3. Buang air kecil atau besar dimana saja secara spontan (bukan di toilet) bisa saja terjadi karena faktor kesehatan seperti sedang menderita diare.

4. Kondisi cuaca dingin atau panas. Pada saat musim dingin atau penghujan, bisa jadi frekuensi buang air kecil menjadi lebih sering, sementara mata mengantuk tidak mau bangun di malam hari. Mengompol di celana menjadi alternatif karena Zakia tidak menggunakan pembalut untuk menampung kotorannya. Kondisi ini bisa normal kembali jika orang tua bisa konsisten memberikan pelayanan dan pendampingan untuk mau buang hajat di toilet secara teratur ketika kondisi kesehatan sudah pulih dan kondisi cuaca sudah stabil kembali. Cuaca panas sering menjadi penyebab untuk tidak mau mengenakan baju. Suhu harus distabilkan terlebih dahulu baru bisa menggunakan baju.
5. Kondisi badannya sendiri seperti mengantuk atau sedang sibuk bermain membuat aktivitas membersihkan diri menjadi terabaikan. Buang air di tempat bermain, tidak sempat ke toilet karena asyik beraktivitas fisik atau sebaliknya karena mengantuk jadi malas untuk bangun di tengah malam ke toilet.

6. Pemahaman anatomi tubuh diperlihatkan dengan menunjuk anggota yang dimaksud. Misalnya, ketika mencuci tangan; "mana tangannya Zakia?" ia mengangkat tangannya sambil menggosok-gosokkan ke atas dan ke bawah.

Tabel 4. Perkembangan Seksual Zakia

\begin{tabular}{|c|c|}
\hline Aspek & Rincian \\
\hline Anatomi tubuh & $\begin{array}{l}\text {-Menyebutkan } \\
\text { nama anggota } \\
\text { tubuh } \\
\text {-Menunjuk } \\
\text { anggota tubuh } \\
\text { yang dimaksud }\end{array}$ \\
\hline Pengenalan diri & $\begin{array}{l}\text {-Menyebutkan } \\
\text { nama panggilan } \\
\text {-Datang bila } \\
\text { dipanggil namanya }\end{array}$ \\
\hline Adab & $\begin{array}{l}\text {-Memasang baju } \\
\text { dengan bantuan } \\
\text {-Memasang celana } \\
\text { dengan bantuan } \\
\text {-Mengangkat } \\
\text { tangan berdoa }\end{array}$ \\
\hline
\end{tabular}


Perkembangan Seksual Anak...

Widia Winata, Khaerunnisa,\&Farihen

\begin{tabular}{|c|c|}
\hline & $\begin{array}{l}\text { ketika mau makan, } \\
\text { tidur } \\
\text {-Cuci tangan, } \\
\text { muka, kaki } \\
\text { sebelum } \\
\text { tidur/gerakan } \\
\text { wudhu }\end{array}$ \\
\hline $\begin{array}{l}\text { Kebersihan } \\
\text { tubuh }\end{array}$ & $\begin{array}{l}\text {-Toilet training; } \\
\text {-Menggosok gigi } \\
\text {-Mencuci tangan } \\
\text { sebelum/sesudah } \\
\text { makan } \\
\text {-Mandi }\end{array}$ \\
\hline
\end{tabular}

\section{Pembahasan}

Perkembangan seksual Zakia dipengaruhi oleh perkembangan aspek lainnya seperti aspek kognitif, sosial emosional dan fisik motorik. Tidak bisa dipungkiri bahwa kematangan aspek lain turut membantu kecakapan dalam perkembangan seksual. Seperti bahasa yang digunakan oleh anak membuka komunikasi antara orang tua dengan anak tentang apa yang dimaksudkan anak. Menurut Vygotsky, unsur bahasa merupakan hal yang sangat penting dalam proses belajar anak. Tanpa bahasa akan sulit anak untuk mempelajari suatu konsep (Vygotsky dalam Papalia, 2009: 32).

Pembiasaan yang dilakukan dalam tindakan kebersihan tubuh dapat menjadi stimulasi agar anak mampu berperilaku bersih setiap hari. Behaviorisme mengatakan conditioning merupakan kondisi yang dilaksanakan terus-menerus sehingga terciptanya perilaku yang dituju pendidik dan anaknya (Papalia, 2009: 29). Kondisi seperti tidak memberikan pembalut (pampers) kepada anak dimaksudkan agar anak mengetahui dan mengalami bahwa membuang kotoran atau fesesnya hanya dilakukan di tempat yang sudah disediakan yaitu toilet bukan di tempat lain apalagi selangkangan atau celana.

Penggunaan pembalut dalam jangka lama bisa megakibatkan anak akan malas ke toilet jika keinginannya untuk buang air sudah muncul. Malas membersihkan kotoran yang menempel pada tubuhnya bahkan rasa kepercayaan diri yang rendah. Efek lain dari sisi kesehatan seperti resiko kanker, tingkat kesuburan menurun, kadar hormon yang kacau, ruam kulit, gatal-gatal, saluran kencing terganggu dan sistem kekebalan tubuh menjadi menurun 
(infosehatwanita.com).

Kemungkinan-kemungkinan resiko pada tubuh dan alat reproduksi anak bisa diminimalisir dengan pelatihanpelatihan yang dapat mengoptimalkan perkembangan seksual anak sejak dini.

Melatih toilet training lebih awal menjadi solusi yang sehat untuk anak dan pendidiknya. Di antara upaya yang bisa dilakukan pada tahap awal pengenalan toilet training adalah:

1. Melihat jadwal buang air anak setiap berapa jam sekali. Jika buang air kecil dilakukan setiap tiga jam sekali maka kondisikan anak untuk mendatangi toilet di jam-jam tersebut secara rutin dan teratur. Basahi jari kaki atau telapak kakinya agar terangsang untuk buang air.

2. Kondisikan toilet atau kamar mandi yang ramah anak. Misalnya gambar dinding dengan motif lucu atau warna yang mencolok untuk menarik perhatian anak. Pilih peralatan mandi yang menarik misalnya kotak sabun berbentuk boneka, sikat gigi menggunakan gagang yang lembut dan lain sebagainya.

3. Respon secepatnya jika anak menunjukkan tanda-tanda mau buang air. Ajak ke toilet dengan menuntun anak agar tidak terburu-buru.

4. Mandi dilakukan dengan senang hati, sambil bermain air dan bernyanyi. Keramas tidak terburu-buru sehingga membuat anak nyaman.

5. Ganti baju atau celana bila anak merasa tidak nyaman.

6. Gosok gigi teratur pagi dan malam hari dengan sikat yang lembut dan pasta yang sesuai untuk anak. Jika anak tidak suka dengan bau atau rasa pasta gigi, orang tua bisa mengganti dengan rasa lain yang lebih diminati. Saat ini di pasaran sudah begitu banyak model sikat gigi dan pasta gigi yang menarik baik dari segi bentuk, rasa, isi dan warnanya.

7. Jangan menyentuh alat vital anak jika tidak diperlukan. Jika disentuh secara sembarangan bisa menyebabkan kerusakan atau lecet pada kulit anak. 
Beberapa kasus pengasuhan yang pernah ada, memainkan alat kelamin anak justru dianggap lelucon dan bahan tertawaan. Hal ini dapat menyebabkan anak kebingungan menghadapi orang yang tertawa padahal tidak seharusnya itu ditertawakan.

8. Cek setiap saat biang keringat yang mungkin saja muncul pada kulit yang tertutup seperti punggung, kening dan dada. Pemberian bedak bayi bisa mengatasi sesaat tetapi jika sudah terlalu banyak bisa membuat anak tidak nyaman dan harus menggunakan salep khusus.

Penanganan kebutuhan anak dari aspek perkembangan seksual ini dapat menumbuhkan rasa nyaman dan aman dalam tumbuh kembang anak. Layaknya rasa kepercayaan awal yang sudah dibentuk orang tua dalam pengasuhan anak sejak bayi, dapat menetap pada proses tahap selanjutnya. Ericson menyebutnya dengan istilah basic trust atau kepercayaan dasar awal kehidupan anak manusia. Jika basic trust ini terus berkembang secara konsisten maka dapat berlanjut dengan autonomy, initiative dan industry di level pubertas (Ericson dalam Papalia, 2009: 27).

Autonomy ditunjukkan dengan kemandirian anak untuk melakukan aktivitasnya, anak mengembangkan inisiatif ketika mencoba hal baru yang ada di hadapannya. Pada usia enam tahun sampai masa pubertas, anak mulai belajar skill yang dibutuhkan dalam menjalani hidupnya ke depan.

\section{KESIMPULAN DAN SARAN}

Berdasarkan hasil penelitian yang sudah dijabarkan, dapat disimpulkan bahwa perkembangan seksual anak usia dua tahun (Zakia) sudah mengalami perkembangan dibanding masa sebelumnya di usia bayi (infant). Fase oral dan sensorimotorik sudah dilalui dan masuk pada fase anal, autonomy dan preoperational. Fase-fase ini menunjukkan kesiapan untuk menghadapi latihan-latihan toilet training.

Pembiasaan (conditioning) yang dilakukan secara konsisten bisa berdampak pada teraturnya anak membersihkan dirinya; menggosok 
gigi, mencuci tangan sebelum makan dan sesudah makan, mencuci tangan, muka dan telapak kaki sebelum tidur, buang air kecil dan besar di toilet, mandi dengan teratur dua kali sehari, menggunakan baju yang sesuai untuk menutupi auratnya. Pengenalan diri sendiri juga dapat dilakukan dengan menyebutkan anggota tubuh sambil bermain dan bernyanyi. Waktu khusus mandi sambil bernyanyi nama-nama anggota tubuh juga bisa dilakukan bersama anak. Adab tentang pergaulan diterapkan secara tepat, misalnya tidak berciuman dengan teman yang lain jenis atau bukan muhrim, tidak menyentuh alat vital secara sembarangan, mengucapkan doa sebelum dan sesudah berkegiatan serta menutup aurat dengan baik.

Perkembangan seksual terkait dengan aspek perkembangan lainnya seperti aspek kognitif, bahasa, fisik motorik dan sosial emosional. Oleh karena itu pengembangan aspek lain berjalan seirama dengan perkembangan seksual anak. Anak tidak bisa melakukan toilet training jika kondisi fisiknya sakit atau kondisi yang bisa menghalangi lainnya.

Atas dasar pertimbangan itulah maka disarankan agar pendidik juga mempelajari tentang pengetahuan aspek perkembangan yang holistik dan komprehensif sehingga ketika berhadapan dengan anak, akan lebih bermakna dan dimengerti apa maunya anak. Pendidik juga harus sabar dan rajin melatih kemampuan-kemampuan dasar anak dalam beraktivitas, berikan kebebasan anak dalam berbuat. Misalnya dalam kegiatan mengelap meja atau mengepel lantai, berikan kesempatan kepada anak untuk membersihkan meja yang kotor. Namun dalam pelaksanaannya tetap diawasi karena anak kadang kala belum memiliki kontak kognitif yang sesuai dengan fisik. Seringkali anak tidak sengaja menjatuhkan benda lain atau justru terpeleset. Tingkat keselamatan dan keamanan terus dijaga seperti kamar mandi yang licin harus diwaspadai ketika pendidik mengajak anak ke kamar mandi.

Saran berikutnya terkait
dengan fasilitas belajar yang


Perkembangan Seksual Anak...

Widia Winata, Khaerunnisa,\&Farihen disediakan orang tua atau pendidik. Membeli barang mainan atau latihan seperti kloset mini untuk melatih kemampuan awal mengedan feses di toilet bisa dianjurkan. Rangsangan siraman air di kaki jika sudah saatnya anak mengeluarkan kotoran air kecilnya juga dapat dilakukan agar anak mengerti bahwa di sini tempatnya membuang hajat.

Penelitian kualitatif tentang perkembangan seksual anak usia dua tahun ini menjadi awal dari penelitian multi years. Landasan fundamental hasil penelitian ini dapat dijadikan penelitian lanjutan dengan tipe penelitian Research and Development $(R \& D)$ di tahun berikut.

\section{DAFTAR PUSTAKA}

Al Magribi, bin Assaid Al Magribi. Begini Seharusnya Mendidik Anak. Jakarta: Darul Haq, 2006.

Delamater, Jhon \& William N. Friedrich. "Human Sexual Development." The Journal Sex Research 11 Januari 2010 Volume 39. hal. 10-14, 2010.

Frankham, Jo. "Sexual Antimonies and Parent/Child Sex Education; Learning from Foreclosure". Sage Journal 1
April 2006 Volume 9. (2) hal 1, 2006).

Garcia, Jhons L. "Frued's Psychosexual Stage Conseption: A Developmental Metaphor for Conselors". Juornal of Conseling and Development. Volume 72. Issue 2. hal 498., 1995.

Kampanye Mulai Bicara untuk Korban Kekerasan Seksual. Metro TV Siaran Mata Najwa. 18 Mei 2017 pukul 22.57.

Kamus Lengkap Bahasa Indonesia. Jakarta: Bintang Indonesia.

KPAI Catat Pelecehan Seksual Dialami Anak Capai 58\%. http://news.okezone.com/read /2016/01/22/337/1294743/kp ai-catat-pelecehan-seksualdialami-anak-capai-58\%.

Moleong, Lexy J. Metodologi Penelitian Kualitatif. Bandung: Remaja Rosdakarya, 2002.

Oxford Learner's Pocket Dictionary. New York: Oxford University Press, 2015.

Papalia, Diane E., Sally Wendkos Olds and Ruth Duskin Feldman. Human Developmen. New York: Mc Graw Hill, 2009.

Paramastri, Supriyati dan Priyanto. Early Prevention Toward Sexual Abuse on Children. Jurnal Psikologi. Volume 37, No. 1, Juni 2010; 1-12. http://jurnal.ugm.ac.id/jpsi/art icle/viewFile/7688/5955.

Pendidikan Seksual untuk Anak. Alodokter.http://www.alodok ter.com/pendidikan-seksualuntuk-anak. 
Volume 11 Edisi 2, November 2017

Peraturan Menteri Pendidikan dan Kebudayaan Republik Indonesia. Nomor 137 tentang Standar Nasional Pendidikan Anak Usia Dini, Tahun 2014.

Reysyahri, Muhammad M. Anak Di Mata Nabi. Jakarta: Al Huda, 2009.

Seefeldt, Carol and Nita Barbour. Early Childhood Education. New York: Macmillan, 1994.
Spradley, James P. Partisipan Observation. New York: Holt Rinehart and Winston, 1980.

10 Dampak Berbahaya Penggunaan Pampers Pada Bayi Lakilaki.

infosehatwanita.com/pascakehamilan/10-dampakberbahaya-penggunaanpampers-pada-bayi-laki-laki33822017.html. 